\title{
GOOD CLINICAL PRACTICE; EDUCATION AS A NECESSITATE FOR RADIOLOGY
}

\author{
Sadaf Ahmed ${ }^{1 \& 2}$, Saima khan ${ }^{1}$, Shamoon Noushad ${ }^{1} \&$ Amna khan ${ }^{1}$ \\ 1. Advance Educational Institute \& Research Centre \\ 2. University of Karachi \\ Corresponding Author Email: saima.aeirc@gmail.com
}

\begin{abstract}
A good clinical practice (GCP) is an ethical and scientific quality act from oldest enduring customs in the historic times of medicine. As the guiding ethical code it is primarily known for its edict to do no harm to the tolerant. However, the complexities of modern medicine research necessitate a more elaborate set of guidelines that address a physician's ethical and scientific responsibilities such as obtaining informed consent or disclosing risks of these biohazards. Our country in last decades has excelled so much in terms of offering training programs for these professional to bridge the gap between the therapeutic interventions and knowledge of these working individuals. We have done a survey on both male and female working in specific hospitals in Karachi. They were interviewed about their skills, duties and knowledge about standards of clinical practice. With reference to the patient care and conditions they were inquired about the medical background, awareness of the sufferer's ailment and ethical concerns like patient safety \& rights. We have found nearly disappointing results as most of these workers were ignorant of the fact that they lack basic knowledge of related responsibilities of concerned patients. Rest of the data also gave the evidence for a huge breach among the awareness, education and realistic approach in this selected workforce. We suggest that caregivers must be aware of indications and have strong medical foundation of the concerned departments where they are serving. We propose the medical education and clinical workshops of this set of serving individuals at ground levels along with the technical fine tuning with the help of case studies and good clinical practice.
\end{abstract}

\section{KEYWORDS}

Good clinical practices, Karachi, hospitals, Ethical guidelines, Patient safety

\section{INTRODUCTION}

ICH-GCP two broad terms which are considered as core of any research project or program, International conference on harmonization and good clinical practice which have now standardized the research and put it into ethical stream are results of the efforts made in early 90s (Otte, 2005; ICH-GCP, 2011). The purpose of ICH-GCP guidelines is to protect human subjects' involvement in research and clinical trials. Back in 1990s the need of research ethics was felt to prevent the human loss and other hazards. This need led to the establishment of ICH in 1990. Meetings were arranged for consecutive 7 years in different countries and regions. In the last meeting the two phases of ICH were set among which one was to make important improvement to reduce the repetition in route of new medicinal development and submission of technical data where as second phase is associated with synchronization of upcoming requirements arising from new research to modernize current ICH guidelines as a precautionary measure for future disharmony of the ethics (Dixon, 1999). Good clinical practice (GCP) is an internationally standardized ethical and scientific quality process for design, conduct, and examination, reporting and recording of clinical trials. The European Union (EU) initiative on GCP altered the world's view of clinical trials and it is obligatory for any clinical trials to be conducted under the stance of GCP guidelines especially for new medicinal products. After World War II in 1947 Nuremberg code was formulated to protect the human atrocities and this code was adopted at the time of human rights declaration and in some countries it was claimed as a law. In 1964 the declaration of Helsinki was formulated by world medical association and was considered as basis of ethical values to provide guidance and education about the safety and benefit of research subjects and it also bound physician to take important measures to safeguard the rights of human subjects involved in research ( Vijayananthan, 2008). The Nuremberg code states that the voluntary consent of human subject is essential to have legal capacity of the person, and to facilitate him for making a decision on his own will to be a part of any ongoing research project. This code proved to be among one of the fundamentals of research ethics (Shuster, 1997). Any research happening under the consideration of ICH-GCP guidelines is supposed to be beneficent for the safety and autonomy of individuals and it guarantee that the data presented in the research is credible along with protection of human subject. These guidelines not only safeguard the human health but it has also turned new stones for the development and approval of any new drug in the pharmaceutical markets (Naqvi, 2013). In 2001 the European parliament approved a directive to conduct in house training for the health professionals to be aware about ICH and GCP principles and their methods of implications. In addition to the pharmaceutical companies the health care associations and medical institutes have also favored the conductance of training sessions regarding ICH and GCP guidelines as it is an exploring gateway to the advancement and betterment of research societies and researchers will have authentic access to their work which will be counted credible for further approaches towards research in any kind of parameters (Kuusisto, 2011). ICH and GCP are projected to provide international standards and amalgamated systems to European Union, Japan and WHO, relevantly to many other countries. The principle of GCP binds a physician to his/her responsibilities, proper handling of new drugs, their adequate implementation, responsibilities of sponsors, abidance to the rules of ethical committee and compensation to subjects and investigators as well as continuation of clinical data (Berntorp, 2001). In view of the ethical concerns the research should be of some value in such a way that it must 
evaluate the diagnostic, therapeutic and pathophysiological involvement. Research should be scientifically available and the subject selection must be fair to carry out in a proper authentic manner and it must have informed consent along with the calculations of benefit-risk ratio with independent review and approval from ethical committee (Emanuel, 2004). Every country has set up its own ethical requirements to be fulfilled and it is mandatory on any individual or institute to follow or fulfill those requirements so the involvement and safeguard of the subjects can be preserved (Gupta, 2006). For past few years the ethical conduction of research has always been the topic of debate in many developing countries. Every research project shall be approved by IRB or ethical committee as it is thought to be one of the major parts of any ongoing research program along with the respect for recruited parties and study communities (Berntorp, 2001).

\section{METHODOLOGY}

A cross sectional observational study was designed to evaluate the awareness knowledge about ICH-GCP guidelines among health professionals and its methods of application. A sample size of 100 was selected regardless of age. SPSS version 7 was used to compute the analysis.

\section{RESULTS}

From the survey we did not get satisfactory results as the ratio of awareness among health professionals was very low. Out of 100 people only $12 \%$ had a little knowledge about good clinical practice where $88 \%$ of the population was not found familiar to the terms ICH and GCP. Furthermore out of $12 \%, 8 \%$ knows about vulnerable population and guidelines specified for clinicians, $16 \%$ had knowledge about consent forms and patient's confidentiality while $25 \%$ were aware of procedural precautions and health hazards respectively.

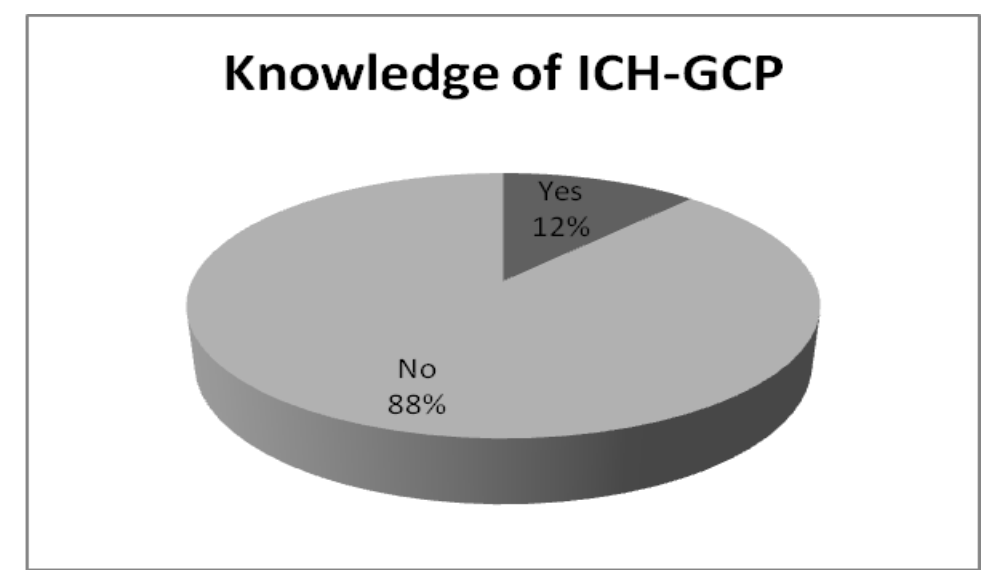

Fig. 1 showing proportion of health professional's familiar to ICH-GCP

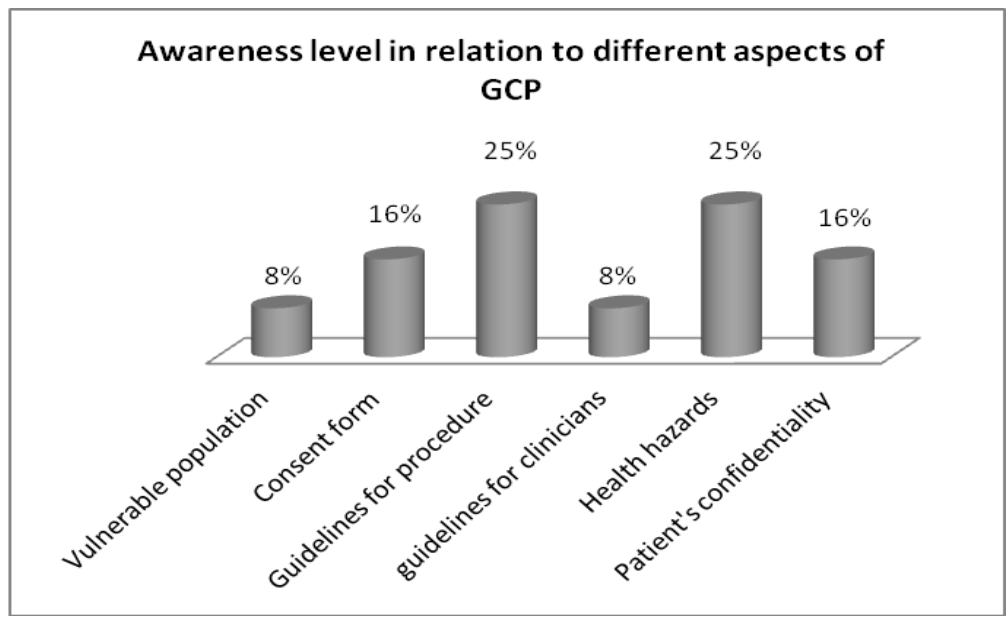

Fig. 2 showing familiarity of health professionals with aspects of patient safety components of GCP

\section{DISCUSSION}

Trials involving human subjects are an essential element of medical research. Such types of research in which humans are enlisted as participants may ask to take testing drug, to give blood or tissue for examination or give information about their habits and life style (Wang, 2003). Such human based research shall be conducted underlining the ethical requirements and measures for 
the safety of individuals taking part in it (Bertholf, 2001). The governance of clinical trials is a significant aspect and it is not ethical if the clinical trials are carried out just for the sake of experiment from a group of subjects without their consent and will. The government of Pakistan is making encouraging steps towards the protection of human subjects so as to establish a good quality research system in the country along with a standard drug regulation system. Yet there is a lot to change as we have come across this ethical standard late in comparison with other developing country (Naqvi, 2013). A question may arise that how can GCP guidelines defend the safety of human subjects involved in research trials. Good clinical practice not only ensures the protection of subjects but it also elaborates in detail the rules and regulations for all bodies engaged in research trials including the sponsors, investigators, supervisors, committee and regulatory patron and it also tells the ways and methods for the mentioned responsibilities and requirements to be fulfilled (Switula, 2000; Grady, 2002). Considering the benefits of ICH implication it not only provides the quality guidelines about drugs and pharmaceutical products but it also benefits the research committees and institution by serving as educational material and references in many Asian countries which are included in non-ICH countries (WHO, 2002) in future the GCP will have beneficial impact on clinical trials occurring in the $3 \mathrm{ICH}$ regions along with other non ICH regions throughout the world. More over it will also offer projected rationale of providing a more economical use of human, animals and material in the field of research and will help to reduce the delay in globalization of newly launched drugs, their development and accessibility (Otte, 2005). Asia has almost 60\% of world's population and therefore it bears the burden of many global diseases. Huge infrastructures in hospitals and a team of trained and provoked medical researchers are contributing an incredible potential for clinical trials in the region. Efforts shall be made in every step to manage the trials in an appropriate way though it is a complex thing to manage but one should not stop trying. The medical research council of UK is of the opinion that failure of many clinical trials is directly related to the mismanagement. On educational basis such policies shall be made to educate health care professionals and researchers too have knowledge about IRBs, ICH, GCP guidelines and their ethical worth to present and publish authentic piece of work (Rahman, 2013).

"Early involvement of the community lays the ground work for the partnership between community and researcher" (Weijer, 1999).

\section{CONCLUSION}

It is attempted to analyse that health professionals should have compulsory knowledge about research and health ethics and about the drugs they are using ton treat the patients. It is mandatory on a physician to be aware about the hazards and benefits of any step he/she makes for the patient and it shall be made necessary to have a consent filled by the subject itself. Besides that a properly designed project must have to clear all the steps of international standards and it has to be reviewed and approved by IRB through proper channel.

\section{REFERENCES}

- Berntorp, E. (2001). Conduct in Clinical trials.

- Bertholf, R. L. (2001). Protecting human research subjects. Annals of Clinical \& Laboratory Science, 31(1), 119-127.

- Branch, S. K. (2005). Guidelines from the international conference on harmonization (ICH). Journal of pharmaceutical and biomedical analysis, 38(5), 798-805.

- Dixon, J. R. (1999). The international conference on harmonization good clinical practice guideline. Quality Assurance: Good Practice, Regulation, and Law, 6(2), 65-74.

- Emanuel, E. J., Wendler, D., Killen, J., \& Grady, C. (2004). What makes clinical research in developing countries ethical? The benchmarks of ethical research. Journal of Infectious Diseases, 189(5), 930-937.

- Grady, C. (2002). Ethical principles in clinical research. Principles and Practice of Clinical Research. Gallin JI. Ed. Academic Press, California.

- Guideline, I. H. T. (2001). Guideline for good clinical practice. J Postgrad Med, 47(1), 45-50.

- ICH-GCP. (2011). Guideline for Good Clinical Practice E6 (R1), June 10, 1996.

- Gupta, M., \& Kohli, K. (2006). Current Regulatory and Ethical Requirements for Conducting Clinical Research in India. Journal, Indian Academy of Clinical Medicine, 7(3).

- Kuusisto, H., Virkki, M., Wuolijoki, E., \& Keränen, T. (2011). Hospital training program increases awareness of Good Clinical Practice (GCP). Contemporary clinical trial

- Naqvi, H. A., \& Hussain, A. (2013). The Clinical Trial Research: How Random is Random?. Journal of the College of Physicians and Surgeons--Pakistan: JCPSP, 23(4), 2392414.

- Ohno, Y. (2002). ICH guidelines-implementation of the 3Rs (refinement, reduction, and replacement): incorporating best scientific practices into the regulatory process. ILAR Journal, 43(Suppl 1), S95-S98.

- Otte, A., Maier-Lenz, H., \& Dierckx, R. A. (2005). Good clinical practice: historical background and key aspects. Nuclear medicine communications, 26(7), 563-574.

- Rahman, S., \& Majumder, M. A. A. (2013). Managing clinical trials in Asia: Issues, threats, opportunities and approaches. South East Asia Journal of Public Health, 2(2), 80-84.

- Shuster, E. (1997). Fifty years later: the significance of the Nuremberg Code. New England Journal of Medicine, 337(20), 1436-1440.

- Switula, D. (2000). Principles of good clinical practice (GCP) in clinical research. Science and engineering ethics, 6(1), 7177.

- Vijayananthan, A., \& Nawawi, O. (2008). The importance of Good Clinical Practice guidelines and its role in clinical trials. Biomed Imaging Interv J, 4(1), e5-e5.

- Wang, H. P., \& Chen, C. Y. (2003). Clinical Trials in Taiwan-Regulatory Achievement and Current Status. Drug Information Journal, 37(4).

- Weijer, C., Goldsand, G., \& Emanuel, E. J. (1999). Protecting communities in research: current guidelines and limits of extrapolation. Nature genetics, 23(3), 275-280.

- World Health Organization. (2002). The Impact of implementation of ICH guidelines in non-ICH countries: report of a WHO meeting, Geneva, 13-15 September 2001. 
Print: ISSN 2307-3748

Online: ISSN 2310-3841 